REVIEW

\title{
Contemporary management of acute coronary syndrome
}

\author{
G A Large
}

Postgrad Med J 2005;81:217-222. doi: 10.1136/pgmj.2004.022590

This review focuses on the modern management of the nonST elevation acute coronary syndromes (unstable angina and non-ST elevation myocardial infarction). Patients with these syndromes are at varying degrees of risk of (re)infarction and death. This risk can be reliably predicted by clinical, electrocardiographic, and biochemical markers. Aspirin, clopidogrel, heparin (unfractionated or low molecular weight), and anti-ischaemic drugs should be offered to all patients, irrespective of the predicted level of risk. Patients at high risk should also receive a glycoprotein $\mathrm{llb} / \mathrm{lll}$ a receptor inhibitor and should undergo early coronary arteriography with a view to percutaneous or surgical revascularisation. Lower risk patients should undergo non-invasive testing. When inducible myocardial ischaemia is exhibited coronary arteriography should follow. When non-invasive testing is negative, a conservative management strategy is safe.

Correspondence to: $\operatorname{Dr} G$ A Large, Department of Cardiovascular Medicine, University Hospital, Derby Road, Nottingham NG7 2UH, UK; adrian.large@virgin. net

Submitted 31 March 2004 Accepted 10 May 2004
A cute coronary syndrome (ACS) is a broad term that encompasses a range of acute clinical manifestations of coronary arteriosclerosis. It has become convention to divide acute coronary syndrome patients into two groups according to whether or not initial 12 lead electrocardiograms show persistent STsegment elevation (fig 1). Its presence correlates well with acute and complete epicardial coronary artery occlusion ${ }^{1}$ and predicts benefit from urgent reperfusion therapy with fibrinolytic drugs $^{2}$ or percutaneous coronary intervention. ${ }^{3}$ In the absence of persistent ST-segment elevation reperfusion therapy confers no benefit and may even be harmful. ${ }^{2}$ In this setting other therapeutic strategies are effective and the purpose of this review is to précis the evidence that underlies the contemporary management of ACS without persistent ST-segment elevation.

\section{RISK STRATIFICATION}

The rate of death, myocardial (re)infarction, or recurrent severe ischaemia early after non-ST elevation acute coronary syndrome (NSTEACS) varies but may be as high as $41 \%{ }^{4}$ The primary goal of therapy is reduce this risk. It has been shown that higher risk demands more aggressive management ${ }^{5-7}$ and so, achieving this goal first requires an estimate to be made of the absolute level of risk. Thereafter a "package" of treatment can be assembled and offered, which is appropriate for the degree of hazard. There is an abundance of clinical study data to guide the clinician risk stratifying the NSTEACS patient. In addition a number of national and international guideline documents have been published to facilitate the process. ${ }^{8-11}$ The thrombolysis in myocardial infarction (TIMI) risk scoring system is a risk stratification tool that can easily be applied at the bedside of the NSTEACS patient (box 1). This risk score, developed by Antman et $a l^{4}{ }^{4}$ was derived by multivariate logistic regression analysis of the TIMI $11 \mathrm{~B}$ trial dataset. ${ }^{12}$ In this and most other risk stratification algorithms, three groups of variables have been used; clinical, electrocardiographic, and biochemical.

\section{Clinical risk stratification}

A number of clinical features have been identified as conferring increased risk of adverse outcome. $^{13}$ The most important are age $>75$ years, rest pain (lasting $>20$ minutes), haemodynamic instability, pulmonary congestion, a new or worsening mitral regurgitant murmur, and the presence of a third heart sound. ${ }^{14}{ }^{15}$ Presentation with NSTEACS in the early aftermath of myocardial infarction (within two weeks) is an additional ominous feature. ${ }^{16}$

\section{Electrocardiographic risk stratification}

A 12 lead ECG is usually the earliest investigation undergone by patients presenting with suspected ACS. Often it serves to confirm the clinical suspicion but its utility reaches further than diagnosis alone. ST-segment depression (or transient ST segment elevation) in particular, demarcates patients at highest risk of adverse outcome and is predictive of three vessel or left main stem coronary disease, or both. ${ }^{17}{ }^{18}$ Furthermore, there seems to be a direct correlation between the extent of ST segment shift and increased risk. ${ }^{19}$ In comparison, T wave inversion without ST segment shift implies an intermediate level of risk and the finding of a normal 12 lead ECG on admission to hospital is a marker of a favourable immediate prognosis. ${ }^{18} 20$

\section{Biochemical risk stratification}

Central to the biochemical risk stratification of NSTEACS patients are the cardiac troponin assays. The cardiac troponins ( $\mathrm{T}$ and $\mathrm{I}$ ) are both highly specific and sensitive markers of myocardial necrosis ${ }^{21}$ and in its absence they are undetectable in serum. Patients with suspected NSTEACS in whom an increase in serum cardiac troponins is detected fair worse than those in whom it is not. Troponin increase is predictive of

Abbreviations: ACS, acute coronary syndrome; NSTEACS, non-ST elevation acute coronary syndrome; TIMI, thrombolysis in myocardial infarction risks scoring system; CABG, coronary artery bypass grafting; UFH, unfractionated heparin; $L M W H$, low molecular weight heparin 
reinfarction and cardiac death. ${ }^{22-24}$ Even the smallest detectable elevations are indicative of increased risk and it has been shown that the level of risk is directly proportional to the degree of increase. ${ }^{25}$ Furthermore, it has become apparent that troponin "positivity" identifies patients who benefit most from treatment with low molecular weight heparins, ${ }^{6}$ platelet glycoprotein IIb/IIIa receptor inhibitors, ${ }^{26}$ and speedy revascularisation. ${ }^{7}$ An important caveat for the clinician to bear in mind regarding the use of cardiac troponin assays relates to the time course of their release from the cytosolic pool. The release kinetics of troponins are such that after myocardial necrosis their appearance in peripheral blood is delayed by three to four hours. It is therefore imperative to appreciate that a single negative troponin assay at the time of a patient's admission cannot always be relied upon to exclude myocardial infarction. In this setting, it is recommended that the test be repeated 6 to 12 hours after admission and after any further episode of chest pain. The practice of omitting immediate troponin estimation on admission (to cut cost) has the potential for delaying the identification of high risk patients and is therefore inappropriate.

Evidence is emerging that "newer" biomarkers may provide prognostic information additional to that available from cardiac troponin assays. Data have been published showing that $B$ type natriuretic peptide (a neurohormone synthesised in ventricular myocardium), ${ }^{27}$ fibrinogen, ${ }^{28}{ }^{29}$ $C$ reactive protein, ${ }^{30-32}$ and soluble CD40 ligand (a marker of platelet activation) $)^{33}$ are all markers of increased risk in the NSTEACS patient. Although yet to be widely adopted into routine practice, the apparent value of these novel markers in predicting recurrent events in troponin negative patients may define their future niche.

\section{DRUG THERAPY}

\section{Antiplatelet and anticoagulant drugs}

The efficacy of aspirin in NSTEACS is well established and has been verified repeatedly in large, randomised, controlled trials. ${ }^{34}{ }^{35}$ It reduces rates of death and myocardial infarction. ${ }^{36}$ Accordingly, immediate treatment with aspirin in a dose of 300-325 mg followed by a maintenance dose of $75-150 \mathrm{mg}$ daily is required in all cases of suspected ACS unless there is an absolute contraindication.

In the recent CURE study of 12562 NSTEACS patients, ${ }^{37}$ the ADP receptor antagonist clopidogrel was shown to reduce the rate of a combined end point of cardiovascular death, non-fatal MI, or stroke from $11.4 \%$ to $9.3 \%$, after a median treatment period of nine months. It is noteworthy that, in contrast with most of the other proven therapies for NSTEACS, the benefit seen with clopidogrel was seen in patients at all levels of baseline risk, including those who were troponin negative and those without ST segment depression on ECG. ${ }^{38}$ As a result it has been recommended that short term treatment with $300 \mathrm{mg}$ of clopidogrel followed by $75 \mathrm{mg}$ daily for at least nine months be offered in all cases of NSTEACS. Some concerns have arisen regarding the finding of an increased risk of major bleeding with clopidogrel in CURE study patients undergoing coronary artery bypass grafting (CABG) within five days of stopping the drug. This has led to the recommendation that clopidogrel be withheld for at least five days before CABG surgery. The need for expedited surgery is the exception rather than the rule and if this is anticipated (because of refractory ischaemia with widespread ST segment shift on ECG or haemodynamic instability) it is reasonable to withhold clopidogrel. If, after subsequent coronary arteriography, a "non-surgical" management strategy is chosen treatment with clopidogrel can be started.

Having been shown to reduce the risk of peri-procedural death and myocardial infarction in patients undergoing percutaneous intervention, ${ }^{39-44}$ inhibitors of the platelet glycoprotein IIb/IIIa receptor have subsequently been extensively studied in patients with acute coronary syndromes. In a metaanalysis, Boersma et al studied a total of 30402 patients with NSTEACS enrolled in six randomised controlled studies. ${ }^{45}$ It was found that early treatment with GPIIb/IIIa inhibitors was associated with an absolute risk reduction in the 30 day rate of

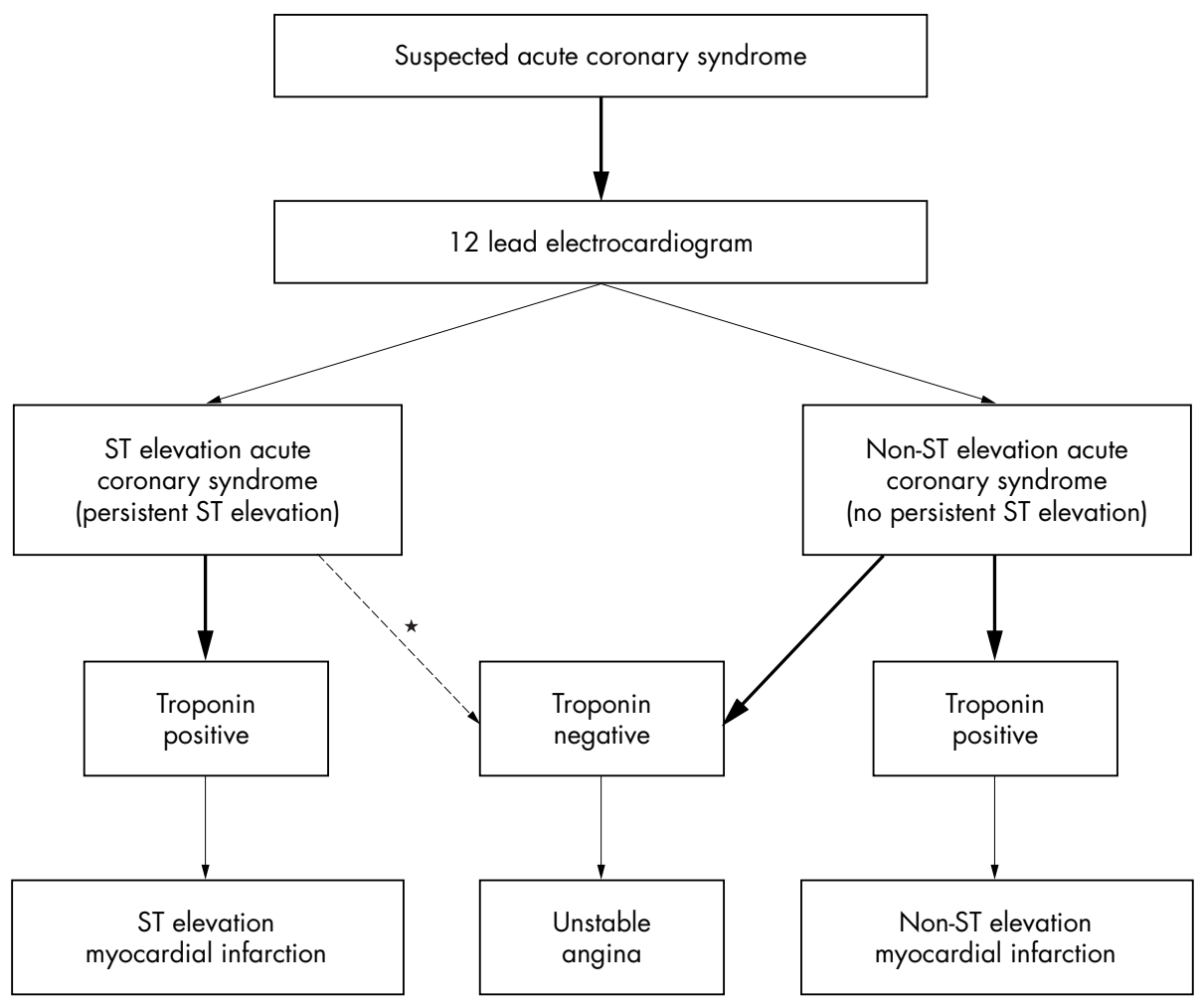

Figure 1 The use of 12 lead electrocardiography and cardiac troponins in the diagnostic evaluation of suspected acute coronary syndrome. * ${ }^{*}$ is unusual to find serial negative troponins in suspected acute coronary syndrome patients whose electrocardiograms show persistent ST segment elevation. 
Box 1 The seven predictor variables of the thrombolysis in myocardial infarction (TIMI) risk scoring system for NSTEACS*

- Age $>65$ years

- Three or more "conventional" risk factors for coronary arteriosclerosis (dyslipidaemia, diabetes mellitus, hypertension, smoking, positive family history)

- Known prior coronary stenosis of $50 \%$ or more

- ST-segment deviation on electrocardiogram at presentation

- At least two anginal events in prior 24 hours

- Use of aspirin in prior seven days

- Raised serum cardiac markers

*For each variable score one point. Rates of adverse outcomes (all cause mortality, myocardial infarction and severe recurrent ischaemia) at 14 days increase with TIMI risk score $(4.7 \%$ for a score of $0 / 1 ; 8.3 \%$ for $2 ; 13.2 \%$ for 3 ; $19.9 \%$ for $4 ; 26.2 \%$ for 5 ; and $40.9 \%$ for $6 / 7$ ).

death or myocardial infarction of $1 \%(p=0.015)$ but at the expense of an increase in the rate of major bleeding complications ( $2.4 \%$ compared with $1.4 \% ; \mathrm{p}<0.0001)$. Separate subgroup analyses showed that benefit from treastment was largely confined to patients who underwent early revascularisation and that troponin negative patients did not benefit. Current guidelines recommend the "upstream" use of intravenous small molecule GPIIb/IIIa inhibitors (eptifibatide or tirofiban) in high risk patients who should also be destined to undergo early coronary arteriography and revascularisation. Benefit is not restricted to patients who undergo percutaneous intervention and is also observed in patients who subsequently undergo CABG. ${ }^{46}{ }^{47}$ Eptifibatide and tirofiban have comparatively short half lives but should be stopped at least four hours before surgery to avoid bleeding complications. Abciximab is not recommended for "upstream" use because in the 7800 patient, GUSTO-IV ACS study its use did not favourably influence the rate of the primary end point of death or myocardial infarction at 30 days. $^{48}$ Moreover, the mortality rate at 48 hours was significantly higher in patients treated with abciximab.

Historically, unfractionated heparin (UFH) has gained widespread acceptance as one of the cornerstone treatments for NSTEACS and its use has been recurrently advocated in published guideline documents. Surprisingly however, the evidence base to support the routine use of UFH in addition to aspirin is limited to a meta-analysis of six randomised controlled studies showing an absolute reduction in risk of death or myocardial infarction of $2.4 \%$, an effect that failed to reach conventional criteria for statistical significance. ${ }^{49}$ The data to support routine use of low molecular weight heparins (LMWH) are more robust. Firstly, a single study has shown the superiority of a LMWH (dalteparin) to placebo in NSTEACS patients..$^{50}$ Secondly, theoretical advantages of LMWH over UFH have been confirmed in clinical end point studies. Two large randomised controlled trials have shown the superiority of enoxaparin to $\mathrm{UFH}^{12}{ }^{51}$ and a meta-analysis of both confirmed a significant reduction in risk of death or myocardial infarction attributable to the use of enoxaparin therapy. ${ }^{52}$ Current guidelines recommend the use of UFH or LMWH in all cases of NSTAECS irrespective of level of risk.

\section{Anti-ischaemic drugs}

Relief of the symptoms of acute myocardial ischaemia requires the use of drugs that correct the imbalance that exists between myocardial oxygen supply and demand. In the absence of contraindications $\beta$ adrenergic block should be first line anti-ischaemic therapy and should be given intravenously in high risk patients, particularly if ischaemia is ongoing. The reasons for this are twofold. Firstly, these agents have a confirmed track record as antianginal agents and secondly, unlike the other groups of antianginals, there is some evidence that their use in NSTEACS may favourably affect prognosis. A meta-analysis of three randomised clinical trials comparing $\beta$ block with placebo in unstable angina showed a significant reduction in rates of progression to acute myocardial infarction but not death, by active treatment. ${ }^{53}$ In addition, extrapolation of data from trials of $\beta$ block in patients with acute or recent myocardial infarction, in which significant reductions in mortality were seen, supports its early use in NSTEACS.

There are no randomised, placebo controlled trials investigating the effect of nitrates on symptoms or prognosis in NSTEACS. A number of small, uncontrolled datasets have been published ${ }^{54}{ }^{55}$ but the routine use of this group of drugs is almost entirely based on anecdotal experience of their efficacy in relieving symptoms. Two large randomised controlled trials have studied the impact of nitrate therapy on outcome in acute coronary syndrome associated with persistent ST segment elevation and in both, no significant benefit from treatment was shown. ${ }^{56}$ It is recommended then that sub-lingual glyceryl trinitrate be given in all cases where ischaemic chest discomfort is present at the time of initial clinical assessment. If symptoms are not relieved rapidly thereafter and after administration of intravenous $\beta$ block, an intravenous nitrate infusion should be started.

Randomised studies of calcium channel blockers in NSTEACS have shown their efficacy in relieving symptoms. $^{5859}$ In addition, diltiazem may have a protective effect $^{6061}$ and there is strong evidence that immediate release nifedipine (a dihydorpyridine) increases mortality rate, particularly if given without $\beta$ block..$^{62}{ }^{63}$ Current guidelines recommend reservation of the dihydropyridine calcium antagonists for use as second or third line therapy after $\beta$ block and nitrates whereas the rate limiting, nondihydropyridine agents (diltiazem and verapamil) may be reasonable alternatives when $\beta$ block is contraindicated.

The potassium channel activator nicorandil reduced the rate of a combined end point of cardiovascular death, nonfatal myocardial infarction, and unplanned hospitalisation for angina in a recent study of 5126 patients with stable angina. ${ }^{64}$ Patel et al reported a smaller study showing that nicorandil significantly reduced the rate of transient myocardial ischaemia or tachyarrhythmias in patients with unstable angina. ${ }^{65}$ This study was not powered to detect differences in clinical outcomes and to date there have been no large randomised controlled studies of this agent in NSTEACS.

\section{CARDIAC CATHETERISATION AND REVASCULARISATION}

An important recent advance in the management of NSTEASC has been the recognition that high risk patients benefit from early (before discharge) invasive investigation and coronary revascularisation compared with a more conservative, "ischaemia guided" strategy, whereby coronary arteriography and revascularisation are reserved for patients with ischaemia refractory to drug therapy or with evidence of inducible ischaemia on early non-invasive testing. Five prospective randomised studies have investigated this issue. The earliest, the TIMI IIIb trial, showed no difference between strategies in terms of rates of myocardial infarction and mortality ${ }^{66}$ Hospital readmission was significantly reduced by the invasive approach. The veterans affairs 


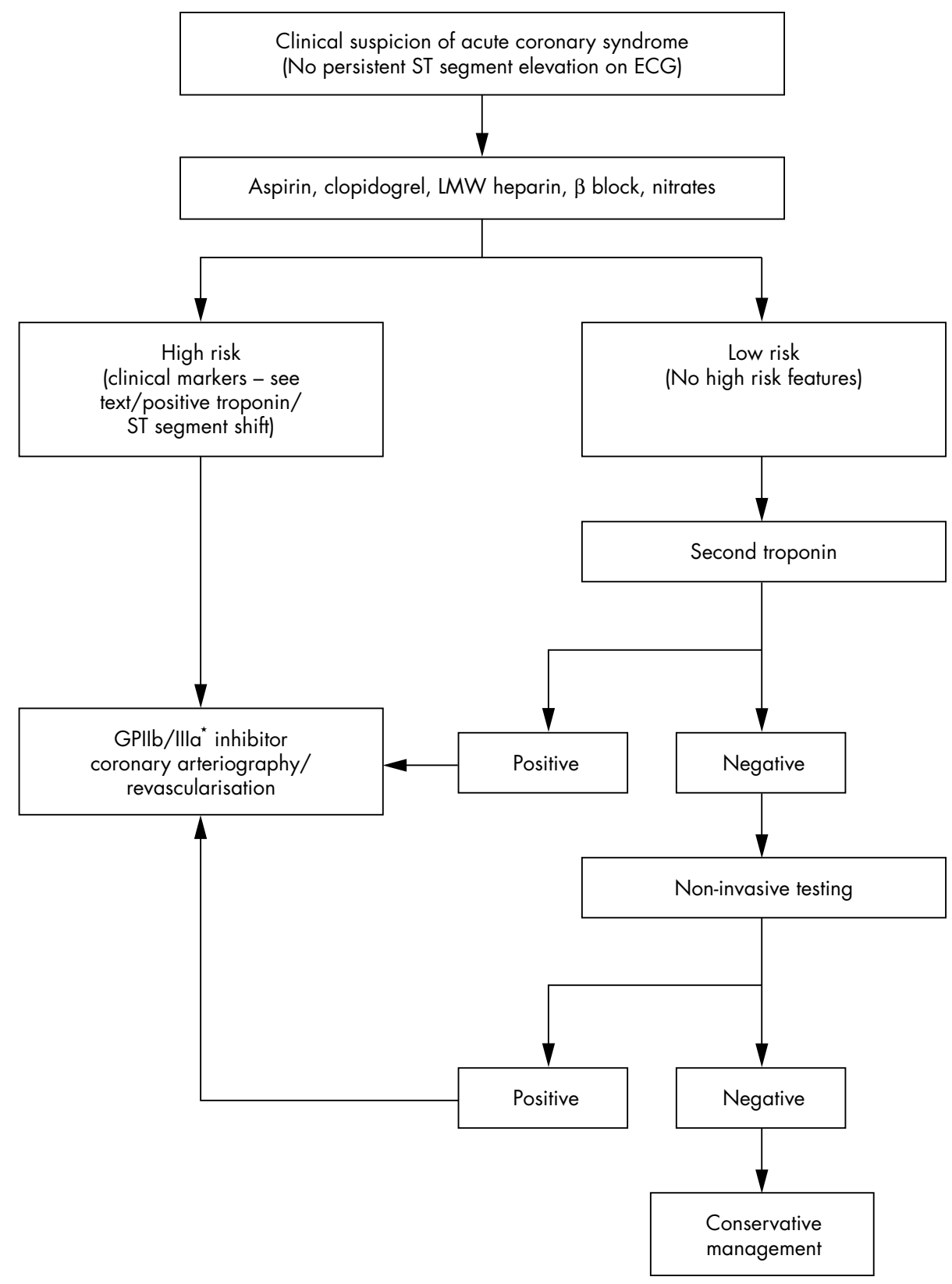

Figure 2 Algorithm to guide the management of patients with non-ST elevation acute coronary syndrome. ${ }^{*}$ Glycoprotein Ilb/llla.

non-Q-wave infarction strategies in hospital (VANQWISH) investigators reported an increased risk of death or non-fatal myocardial infarction with an early invasive strategy. ${ }^{67}$ This may be explained by the unusually high 30 day mortality rate after CABG in this study (12\%).

Both the TIMI IIIB and VANQWISH trials were conducted before the routine use of stents and GPIIb/IIIa inhibitors during percutaneous coronary intervention. As such, the results have to be interpreted with caution in the current day. Three subsequent studies have all shown superiority of early, "modern" invasive management. The fragmin and fast revascularisation during instability in coronary artery disease (FRISC) II study showed a significant reduction in all cause mortality and myocardial infarction at one year follow up, attributable to an invasive strategy. ${ }^{68}$ The TACTICS-TIMI 18 investigators randomised 2220 patients to early coronary arteriography followed by revascularisation as appropriate or a more conservative strategy in which catheterisation was only performed for recurrent ischaemia or positive stress testing. ${ }^{7}$ All patients received tirofiban for 48 hours before randomisation and cardiac catheterisation was carried out comparatively early (at a mean interval of 22 hours after randomisation) compared with the FRISC II study (mean interval six days). Again a benefit in favour of the invasive strategy was found with an absolute risk reduction of 3.5\% in the rate of the primary end point (death, non-fatal myocardial infarction, or rehospitalisation for ACS). Of note, this benefit was restricted to high risk patients-that is, those with TIMI risk score $\geqslant 3$, raised troponins, or ST segment deviation. Most recently, Fox et al published the results of the randomised intervention trial of unstable angina (RITA) 3 study. ${ }^{69}$ All 1810 patients studied were treated with subcutaneous enoxaparin and in the invasive arm, cardiac catheterisation took place at a mean of two days after enrolment. A primary end point of death, (re)infarction, or refractory angina at four months was prespecified and was observed in $9.6 \%$ of patients in the invasive arm compared with $14.5 \%$ of those in the conservative $\operatorname{arm}(p=0.001)$. 


\section{Box 2 Key points}

- Patients presenting with NSTEACS are at varying degrees of risk of myocardial (re)infarction and death.

- Early risk stratification is central to the choice of appropriate treatments.

- High risk is demarcated by clinical lage $>75$ years, rest pain, haemodynamic instability, pulmonary congestion, new or worsening mitral regurgitation, third heart sound, or recent myocardial infarction), electrocardiographic (ST segment shift), and biomarker (troponin positivity) abnormalities.

- Patients at all levels of risk should be treated with aspirin, clopidogrel, heparin (unfractionated or low molecular weight), and anti-ischaemic drugs.

- High risk patients should receive a small molecule, llb/ Illa inhibitior (eptifibatide or tirofiban) and should be offered early (in-patient) coronary arteriography with a view to a revascularisation procedure.

- Patients at lower risk should undergo early, noninvasive testing with coronary arteriography reserved for those in whom inducible myocardial ischaemia is unveiled.

The remarkably consistent results observed by the FRISC II, TACTICS-TIMI 18, and RITA 3 investigators form a large, concrete evidence base on which it is recommended that inpatient coronary arteriography and revascularisation should be made available to all high risk NSTEACS patients. Low risk patients can be safely managed with an initial conservative approach with cardiac catheterisation reserved for those who develop recurrent ischaemia or who subsequently have a positive stress test.

\section{CONCLUSIONS AND RECOMMENDATIONS}

Figure 2 shows a suggested algorithm to guide the management of suspected NSTEACS. Aspirin, clopidogrel, heparin (UFH or LMWH), and a $\beta$ blocker should be on offer to all patients. Aspirin should be continued indefinitely and clopidogrel for at least nine months. Early risk stratification should guide the choice of further therapies. High risk status demands an aggressive management strategy including treatment with a small molecule GPIIb/IIIa inhibitor followed by coronary arteriography and revascularisation. Patients at lower risk should undergo early, non-invasive testing for inducible myocardial ischaemia, followed by coronary arteriography when such testing is positive. Finally, the secondary preventative advice and interventions that apply in general to patients with any clinical manifestation of coronary arteriosclerosis should be made available to all ACS patients. Advice regarding smoking cessation, diet, and exercise should be given. In most cases, additional therapy with lipid lowering agents (statins) and an angiotensin converting enzyme inhibitor will also be required.

Conflicts of interest: none.

\section{REFERENCES}

1 Hauser AM, Gangadharan V, Ramos RG, et al. Sequence of mechanical, electrocardiographic and clinical effects of repeated coronary artery occlusion in human beings: echocardiographic observations during coronary angioplasty. J Am Coll Cardiol 1985;5:193-7.

2 Fibrinolytic Therapy Trialists' (FTT) Collaborative Group. Indications for fibrinolytic therapy in suspected acute myocardial infarction: collaborative overview of early mortality and major morbidity results from all randomised trials of more than 1000 patients. (Erratum in Lancet 1994;343:742). Lancet 1994;343:311-22.
3 Weaver WD, Simes RJ, Betriu A, et al. Comparison of primary coronary angioplasty and intravenous thrombolytic therapy for acute myocardial infarction: a quantitative review. (Erratum in JAMA 1998;279:1876). JAMA 1997;278:2093-8.

4 Antman EM, Cohen M, Bernink PJ, et al. The TIMI risk score for unstable angina/non-ST elevation Ml: A method for prognostication and therapeutic decision making. JAMA 2000;284:835-42.

5 Morrow DA, Antman EM, Snapinn SM, et al. An integrated clinical approach to predicting the benefit of tirofiban in non-ST elevation acute coronary syndromes. Application of the TIMI risk score for UA/NSTEMI in PRISM-PLUS. Eur Heart J 2002;23:223-9.

6 Lindahl B, Venge P, Wallentin L. Troponin T identifies patients with unstable coronary artery disease who benefit from long-term antithrombotic protection. Fragmin in Unstable Coronary Artery Disease (FRISC) Study Group. J Am Coll Card 1997;29:43-8.

7 Cannon CP, Weintraub WS, Demopoulos LA, et al. Comparison of early invasive and conservative strategies in patients with unstable coronary syndromes treated with the glycoprotein Ilb/Illa inhibitor tirofiban. NEngl J Med 2001;344:1879-87

8 Anonymous. Guideline for the management of patients with acute coronary syndromes without persistent ECG ST segment elevation. British Cardiac Society Guidelines and Medical Practice Committee and Royal College of Physicians Clinical Effectiveness and Evaluation Unit. Heart 2001;85:133-42.

9 Bertrand ME, Simoons ML, Fox KA, et al. Management of acute coronary syndromes in patients presenting without persistent ST-segment elevation. (Erratum in Eur Heart J 2003;24:1174-5). Eur Heart J 2002;23:1809-40.

10 Braunwald E, Antman EM, Beasley JW, et al. ACC/AHA guidelines for the management of patients with unstable angina and non-ST-segment elevation myocardial infarction. A report of the American College of Cardiology/ American Heart Association Task Force on Practice Guidelines (Committee on the Management of Patients With Unstable Angina). (Erratum in J Am Coll Cardiol 2001;38:294-5). J Am Coll Cardiol 2000;36:970-1062.

11 Braunwald E, Antman EM, Beasley JW, et al. ACC/AHA 2002 guideline update for the management of patients with unstable angina and non-STsegment elevation myocardial infarction--summary article: a report of the American College of Cardiology/American Heart Association task force on practice guidelines (Committee on the Management of Patients With Unstable Angina). J Am Coll Cardiol 2002;40:1366-74.

12 Antman EM. TIMI 11B. Enoxaparin versus unfractionated heparin for unstable angina or non-Q-wave myocardial infarction: a double-blind, placebocontrolled, parallel-group, multicenter trial, Rationale, study design, and methods. Thrombolysis in Myocardial Infarction (TIMI) 11 B Trial Investigators. Am Heart J 1998; 135:S353-60.

13 Braunwald E. Unstable angina. A classification. Circulation 1989:80:410-14.

14 van Miltenburg-van Zijl AJ, Simoons ML, Veerhoek RJ, et al. Incidence and follow-up of Braunwald subgroups in unstable angina pectoris. J Am Coll Cardiol 1995;25:1286-92.

15 Braunwald $\mathbf{E}$, Jones RH, Mark DB, et al. Diagnosing and managing unstable angina. Agency for Health Care Policy and Research. Circulation 1994;90:613-22

16 Scirica BM, Cannon CP, McCabe CH, et al. Prognosis in the thrombolysis in myocardial ischemia III registry according to the Braunwald unstable angina pectoris classification. Am J Cardiol 2002:90:821-6.

17 Cannon $\mathrm{CP}, \mathrm{McC}$ abe $\mathrm{CH}$, Stone $\mathrm{PH}$, et al. The electrocardiogram predicts one-year outcome of patients with unstable angina and non- $Q$ wave myocardial infarction: results of the TIMI III registry ECG ancillary study. Thrombolysis in myocardial ischemia. J Am Coll Cardiol 1997;30:133-40.

18 Diderholm E, Andren B, Frostfeldt G, et al. ST depression in ECG at entry indicates severe coronary lesions and large benefits of an early invasive treatment strategy in unstable coronary artery disease; the FRISC II ECG substudy. The fast revascularisation during instability in coronary artery disease. Eur Heart J 2002;23:41-9.

19 Kaul P, Newby LK, Fu Y, et al. Troponin T and quantitative ST-segment depression offer complementary prognostic information in the risk stratification of acute coronary syndrome patients. J Am Coll Cardiol 2003;41:371-80.

20 Nyman I, Areskog M, Areskog NH, et al. Very early risk stratification by electrocardiogram at rest in men with suspected unstable coronary heart disease. The RISC Study Group. J Intern Med 1993;234:293-301.

21 Wu AH, Apple FS, Gibler WB, et al. National Academy of Clinical Biochemistry Standards of Laboratory Practice: recommendations for the use of cardiac markers in coronary artery diseases. Clin Chem 1999:45: 1104-21.

22 Ohman EM, Armstrong PW, Christenson RH, et al. Cardiac troponin T levels for risk stratification in acute myocardial ischemia. GUSTO IIA Investigators. N Engl J Med 1996;335:1333-41.

23 Lindahl B, Venge P, Wallentin L. Relation between troponin T and the risk of subsequent cardiac events in unstable coronary artery disease. The FRISC study group. Circulation 1996;93:1651-7.

24 Wu AH, Abbas SA, Green S, et al. Prognostic value of cardiac troponin T in unstable angina pectoris. Am J Cardiol 1995;76:970-2.

25 Antman EM, Tanasijevic MJ, Thompson B, et al. Cardiac-specific troponin I levels to predict the risk of mortality in patients with acute coronary syndromes. N Engl J Med 1996;335:1342-9.

26 Heeschen C, Hamm CW, Goldmann B, et al. Troponin concentrations for stratification of patients with acute coronary syndromes in relation to therapeutic efficacy of tirofiban. PRISM Study Investigators. Platelet receptor inhibition in ischemic syndrome management. Lancet 1999;354:1757-62. 
27 de Lemos JA, Morrow DA, Bentley JH, et al. The prognostic value of B-type natriuretic peptide in patients with acute coronary syndromes. N Engl J Med 2001;345:1014-21

28 Becker RC, Cannon CP, Bovill EG, et al. Prognostic value of plasma fibrinogen concentration in patients with unstable angina and non-Q-wave myocardial infarction (TIMI IIIB trial). Am J Cardiol 1996;78:142-7.

29 Toss H, Lindahl B, Siegbahn A, et al. Prognostic influence of increased fibrinogen and C-reactive protein levels in unstable coronary artery disease. FRISC Study Group. Fragmin during instability in coronary artery disease. Circulation 1997:96:4204-10.

30 Wallentin L, Husted S, Kontny F, et al. Long-term low-molecular-weight heparin (Fragmin) and/or early revascularization during instability in coronary artery disease (the FRISC II study). Am J Cardiol 1997;80:61-3E.

31 Heeschen C, Hamm CW, Bruemmer J, et al. Predictive value of C-reactive protein and troponin $\mathrm{T}$ in patients with unstable angina: a comparative analysis. CAPTURE Investigators. Chimeric c7E3 antiplatelet therapy in unstable angina refractory to standard treatment trial. J Am Coll Cardiol 2000;35: 1535-42.

32 Lenderink T, Boersma E, Heeschen C, et al. Elevated troponin T and C-reactive protein predict impaired outcome for 4 years in patients with refractory unstable angina, and troponin T predicts benefit of treatment with abciximab in combination with PTCA. Eur Heart J 2003;24:77-85.

33 Heeschen C, Dimmeler S, Hamm CW, et al. Soluble CD40 ligand in acute coronary syndromes. N Engl J Med 2003;348:1 104-11.

34 Theroux P, Ouimet H, McCans J, et al. Aspirin, heparin, or both to treat acute unstable angina. N Engl J Med 1988;319:1105-11.

35 Theroux P, Waters D, Qiu S, et al. Aspirin versus heparin to prevent myocardial infarction during the acute phase of unstable angina. Circulation 1993;88:2045-8.

36 Anonymous. Collaborative meta-analysis of randomised trials of antiplatelet therapy for prevention of death, myocardial infarction, and stroke in high risk patients. (Erratum in BMJ 2002;324:141). BMJ 2002;324:71-86.

37 Yusuf S, Zhao F, Mehta SR, et al. Effects of clopidogrel in addition to aspirin in patients with acute coronary syndromes without ST-segment elevation. (Erratum in N Engl J Med 2001;345:1716). N Engl J Med 2001;345:494-502.

38 Budaj A, Yusuf S, Mehta SR, et al. Benefit of clopidogrel in patients with acute coronary syndromes without ST-segment elevation in various risk groups. Circulation 2002;106:1622-6.

39 The EPISTENT Investigators. Randomised placebo-controlled and balloonangioplasty-controlled trial to assess safety of coronary stenting with use of platelet glycoprotein-llb/Illa blockade. Evaluation of platelet $\mathrm{Ilb} / \mathrm{llla}$ inhibitor for stenting. Lancet 1998;352:87-92.

40 The EPILOG Investigators. Platelet glycoprotein Ilb/Illa receptor blockade and low-dose heparin during percutaneous coronary revascularization. N Engl J Med 1997;336:1689-96.

41 Anonymous. Randomised placebo-controlled trial of effect of eptifibatide on complications of percutaneous coronary intervention: IMPACT-II. Integrilin to minimise platelet aggregation and coronary rhrombosis-II. Lancet 1997;349:1422-8.

42 Anonymous. Randomised placebo-controlled trial of abciximab before and during coronary intervention in refractory unstable angina: the CAPTURE study. (Erratum in Lancet 1997;350:744). Lancet 1997;349:1429-35.

43 The RESTORE Investigators. Effects of platelet glycoprotein Ilb/Illa blockade with tirofiban on adverse cardiac events in patients with unstable angina or acute myocardial infarction undergoing coronary angioplasty. Randomized efficacy study of tirofiban for outcomes and restenosis. Circulation 1997;96:1445-53.

44 The EPIC Investigation. Use of a monoclonal antibody directed against the platelet glycoprotein Ilb/Illa receptor in high-risk coronary angioplasty. N Engl J Med 1994;330:956-61

45 Boersma E, Harrington RA, Moliterno DJ, et al. Platelet glycoprotein Illb/llla inhibitors in acute coronary syndromes: a meta-analysis of all major randomised clinical trials. (Erratum in Lancet 2002;359:2120). Lancet 2002;359:189-98.

46 Dyke CM, Bhatia D, Lorenz TJ, et al. Immediate coronary artery bypass surgery after platelet inhibition with eptifibatide: results from PURSUIT. Platelet glycoprotein Ilb/Illa in unstable angina: receptor suppression using integrelin therapy. Ann Thorac Surg 2000;70:866-71, 871-2.

47 Marso SP, Bhatt DL, Roe MT, et al. Enhanced efficacy of eptifibatide administration in patients with acute coronary syndrome requiring in-hospital coronary artery bypass grafting. PURSUIT Investigators. Circulation 2000;102:2952-8.

48 Simoons ML, Investigators GI-A. Effect of glycoprotein Ilb/Illa receptor blocker abciximab on outcome in patients with acute coronary syndromes without early coronary revascularisation: the GUSTO IV-ACS randomised trial. Lancet $2001 ; 357: 1915-24$
49 Oler A, Whooley MA, Oler J, et al. Adding heparin to aspirin reduces the incidence of myocardial infarction and death in patients with unstable angina. A meta-analysis. JAMA 1996;276:811-15.

50 Fragmin During Instability in Coronary Artery Disease (FRISC) Study Group Low-molecular-weight heparin during instability in coronary artery disease. Lancet 1996;347:561-8

51 Cohen M, Demers C, Gurfinkel EP, et al. Low-molecular-weight heparins in non-ST-segment elevation ischemia: the ESSENCE trial. Efficacy and safety of subcutaneous enoxaparin versus intravenous unfractionated heparin, in nonQ-wave coronary events. Am J Cardiol 1998;82:19-24L.

52 Antman EM, Cohen M, Radley D, et al. Assessment of the treatment effect of enoxaparin for unstable angina/non-Q-wave myocardial infarction. TIMI 11 B-ESSENCE meta-analysis. Circulation 1999;100:1602-8.

53 Yusuf S, Wittes J, Friedman L. Overview of results of randomized clinical trials in heart disease. II. Unstable angina, heart failure, primary prevention with aspirin, and risk factor modification. JAMA 1988;260:2259-63

54 Kaplan K, Davison R, Parker M, et al. Intravenous nitroglycerin for the treatment of angina at rest unresponsive to standard nitrate therapy. Am J Cardiol 1983:51:694-8.

55 Roubin GS, Harris PJ, Eckhardt I, et al. Intravenous nitroglycerine in refractory unstable angina pectoris. Aust N Z J Med 1982;12:598-602.

56 ISIS-4 (Fourth International Study of Infarct Survival) Collaborative Group. ISIS-4: a randomised factorial trial assessing early oral captopril, oral mononitrate, and intravenous magnesium sulphate in 58,050 patients with suspected acute myocardial infarction, Lancet 1995;345:669-85.

57 Gruppo Italiano per lo Studio della Sopravvivenza nell'infarto Miocardico GISSI-3: effects of lisinopril and transdermal glyceryl trinitrate singly and together on 6-week mortality and ventricular function after acute myocardial infarction. Lancet 1994:343:1115-22.

58 Theroux $\mathbf{P}$, Taeymans $Y$, Morissette $D$, et al. A randomized study comparing propranolol and diltiazem in the treatment of unstable angina. J Am Coll Cardiol 1985;5:717-22

59 Parodi O, Simonetti I, Michelassi C, et al. Comparison of verapamil and propranolol therapy for angina pectoris at rest: a randomized, multiplecrossover, controlled trial in the coronary care unit. Am Cardiol 1986;57:899-906.

60 Gibson RS, Hansen JF, Messerli F, et al. Long-term effects of diltiazem and verapamil on mortality and cardiac events in non-Q-wave acute myocardia infarction without pulmonary congestion: post hoc subset analysis of the multicenter diltiazem postinfarction trial and the second Danish verapamil infarction trial studies. Am J Cardiol 2000;86:275-9.

61 Gibson RS, Young PM, Boden WE, et al. Prognostic significance and beneficial effect of diltiazem on the incidence of early recurrent ischemia after non-Q-wave myocardial infarction: results from the multicenter diltiazem reinfarction study. Am J Cardiol 1987;60:203-9.

62 Yusuf S, Held P, Furberg C. Update of effects of calcium antagonists in myocardial infarction or angina in light of the second Danish verapamil infarction trial (DAVIT-II) and other recent studies. Am J Cardiol 1991;67:1295-7.

63 Psaty BM, Heckbert SR, Koepsell TD, et al. The risk of myocardial infarction associated with antihypertensive drug therapies. JAMA 1995;274:620-5.

64 group IS. Effect of nicorandil on coronary events in patients with stable angina: the impact of nicorandil in angina (IONA) randomised trial. (Erratum in Lancet 2002;360:806). Lancet 2002;359:1269-75.

65 Patel DJ, Purcell HJ, Fox KM. Cardioprotection by opening of the K(ATP) channel in unstable angina. Is this a clinical manifestation of myocardial preconditioning? Results of a randomized study with nicorandil. CESAR 2 investigation. Clinical European studies in angina and revascularization. Eur Heart J 1999;20:51-7

66 Anonymous. Effects of tissue plasminogen activator and a comparison of early invasive and conservative strategies in unstable angina and non- $Q$-wave myocardial infarction. Results of the TIMI IIIB trial. Thrombolysis in myocardial ischemia. Circulation 1994;89:1545-56.

67 Boden WE, O'Rourke RA, Crawford MH, et al. Outcomes in patients with acute non- $Q$-wave myocardial infarction randomly assigned to an invasive as compared with a conservative management strategy. Veterans Affairs non-QWave Infarction Strategies in Hospital (VANQWISH) Trial Investigators. (Erratum in N Engl J Med 1998;339:1091). N Engl J Med 1998;338:1785-92.

68 Fragmin and Fast Revascularisation during Instability in coronary artery disease Investigators. Invasive compared with non-invasive treatment in unstable coronary-artery disease: FRISC II prospective randomised multicentre study. Lancet 1999;354:708-15.

69 Fox KA, Poole-Wilson PA, Henderson RA, et al. Interventional versus conservative treatment for patients with unstable angina or non-ST-elevation myocardial infarction: the British Heart Foundation RITA 3 randomised trial. Randomized intervention trial of unstable angina. Lancet 2002;360:743-51. 